In conclusion, may we suggest that the $a, b, c$ axes, as chosen by Cox, Shorter and Wardlaw, be called $b, c$ and $a$, in accordance with the usual convention. H. Brasseur.

A. DE Rassenfosse.

Institut de minéralogie et

Institut W. Spring,

Université de Liége. Jan. 18.

${ }^{1}$ Cox, E. G., Shorter, A. J., and Wardlaw, W., Nature, _\$9, 71 (1937).

'Rammelsberg, C. F., Kryst. Chemie, 208 (1855).

'de Marignac, Ch., Ann. des Mines, (5), 12-16 (1857).

- Streng, A., Neues Jahrbuch für Miner., 2, 142 (1882).

${ }^{8}$ Richardson, Amer. Chem. J., 14, 89 (1892).

"Groth, P., "Chemische Krystallographie", 1, 356.

'MacGillsvry, C. H., de Wilde, J. H., and Bijvoet, J. U., Z. Krist., A, 100,212 (1938).

\section{Direct Perception of Pigment in the Nerve Tissue of} Human Retina

DURING spectroscopic study of a flavoprotein compound in heart muscle preparation, it was noticed that two diffuse absorption bands of the pigment remained always perceptible, however dilute was the preparation or thin the layer examined. Further observations have revealed that these two bands remain perceptible even in the absence of muscle preparations. Moreover, examination with a small dispersion spectroscope of any source of artificial light shows the presence of two diffuse absorption bands lying at about $495 \mathrm{~m} \mu$ and $455 \mathrm{~m} \mu$. The first band is more distinctly visible at a lower intensity of light, while the second band can be more easily perceived when the light passes through a suitable filter such as a solution of ammoniacal copper sulphate or Wratten filter D.

In order to see these bands, it is essential to use a very low dispersion spectroscope such as a microspectroscope ocular attached to a microscope or a prism pocket spectroscope and a source of light giving a continuous spectrum. The relative intensities and positions of these bands remain constant and are independent of either the optical system or the source of light. This clearly indicates that the absorption bands are not due to the instruments but to a substance present in the observer's eye and lying on the path of rays from the light source to the sensitive portion of the retina. As the cornea, lens, aqueous and vitreous fluids are devoid of any perceptible colouring matter, the pigment responsible for the absorption bands must be present in the retina itself, in the nerve tissue lying in front of the visual cells (cones) and most probably in the macula lutea and fovea centralis.

The presence of this pigment in the retina can also be deduced from an examination of the visibility data obtained in the 'step-by-step' matching of the intensities of two adjacent spectral regions. In every case these data, whether for normal ${ }^{1,2}$ or for the colour-blind ${ }^{3}$ eye, reveal two distinct depressions in the visibility curve. These two depressions, ascribed ${ }^{2}$ to a pigment present probably in the optical path of the eye, lie at about $495 \mathrm{~m} \mu$ and $455 \mathrm{~m} \mu$, occupying therefore the same positions as the absorption bands described above.

As to the nature of this pigment, we can suggest only that it may be either a flavin or a carotinoid compound, or possibly a mixture of both and present in the thin layer of nerve tissue of the macula in a concentration sufficiently high to give a perceptible absorption spectrum. In fact, flavin and its derivatives $^{4}$ as well as $\beta$-carotene ${ }^{5}$ have been obtained from ox retina. Both pigments have somewhat similar absorption in the region of the spectrum occupied by the above bands. However, the exact nature of the substance responsible for the perception of these two absorption bands will only be solved by a careful study of the pigments obtained directly from the macula lutea of the human eye.

The two absorption bands described above represent, so far, the only slight discontinuities which the eye can perceive in the otherwise continuous spectrum of an artificial source of light. They denote only a very slight imperfection in the eye caused by the presence of pigments in the nerve tissue of the retina itself, an imperfection which is highly magnified by the use of a small dispersion spectroscope.

This observation also serves as warning against the use of the direct method of spectroscopic examination in the general survey of flavin or carotene distribution in different tissues and their extracts. In fact, if this method is used, it will not be possible to detect any cells completely devoid of these pigments.

\section{KeILIN.}

E. L. Sмiтh.

(Guggenheim Fellow).

Molteno Institute,

University of Cambridge. Feb. 1 .

' Gibson, K. S., and Tyndall, E. P. T., Bur. Stand. Sci. Papers, 13 131 (1923).

Fedorow, N. T., and Fedorowa, W. I., C.R. Acad. Sci., U.R.S.S. 2, 377 (1936).

${ }^{3}$ Hecht, S., and Shlaer, S., J. Gen. Physiol., 20, 57 (1936).

- Brunner, O and Baroni, E. Sitzber. Akad. Wiss. Wien, Math. natw. Klasse, ilC., 145, 484 (1936).

Brunner, O., Baroni, E., and Kleinau, W., Z. physiol. Chem., 236. 257 (1935).

\section{Differentiation of Disaccharide-splitting Enzymes}

WEIDENHAGEN's theory of the specificity of glucosidases and disaccharases ${ }^{1}$, as opposed to the theory of specificity of Leibowitz ${ }^{2}$, depends largely upon the claim that the maltose-splitting factor of taka-diatase is an alpha-glucosidase identical with the sucrose-splitting factor (glucosucrase). According to Leibowitz, on the other hand, taka-maltase is a specific glucomaltase, inert to alpha-methyl-glucoside and distinct from the taka-sucrase.

Recently ${ }^{3}$ we reported the possibility of freeing taka-maltase from accidentally accompanying alphamethyl-glucoside splitting enzyme on the basis of the thermostability of the former. It has now been found that on brief incubation at $p H \mathbf{H} \cdot 5$ the heat-stable taka-maltase retains full activity whilst taka-sucrase is completely destroyed. Hence it follows that takamaltase and taka-sucrase are two distinct enzymes. Consequently, the theory of Weidenhagen, against which serious objections have already been raised, may now be considered refuted.

$$
\begin{gathered}
\text { Department of Hygiene and } \\
\text { Bacteriology, } \\
\text { Hebrew University, } \\
\text { Jerusalem. } \\
\text { Jan. 22. }
\end{gathered}
$$

J. LEIBOWITZ

S. Hestrin. \footnotetext{
Z. physiol. Chem., 216, 255 (1933), and elsewhere.

${ }^{2}$ Leibowitz, Z. physiol. Chem., 149, 184 (1925); Leibowitz and Mechlinsky, ibid., 154, 64 (1926).
}

Weidenhagen, “Ergebnisse der Enzymforschung”, vol. 1 (1932)

${ }^{3}$ Leibowitz and Hestrin, NATURE, 141, 552 (1938). 